\title{
Assessment of seismic hazard for the Sannio-Matese area, Southern Italy (Project «TERESA»)
}

\author{
Dieter Mayer-Rosa $\left({ }^{1}\right)$, Dario Slejko $\left.{ }^{(}\right)$and Gaetano Zonno $\left({ }^{3}\right)$ \\ (') Institut für Geophysik, ETH-Zürich, Switzerland \\ (2) Osservatorio Geofisico Sperimentale, Trieste, Italia \\ (3) Istituto per la Geofisica della Litosfera, CNR, Milano, Italia
}

\begin{abstract}
In the European Seismological Commission's working group on «Test Regions for European Seismic-Hazard Assessment (TERESA)» scientists of 10 European countries cooperated towards a common working goal: methods and experience gathered in the different countries should be applied and compared for two selected test areas in Europe: 1) the Sannio-Matese region in southern Italy, showing high seismicity and 2) the border region between Belgium, Netherlands and Germany, with relatively low seismicity. This paper summarizes the results for the test area Sannio-Matese.

Most of the participants preferred statistical or probabilistic procedures to assess seismic hazard. The results have been presented in terms of probability of occurrence for intensity as ground-motion parameter at 5 different sites. The most influencing factor was found in the initial preparation of the input data and parameters within the different approaches. Therefore, most of the efforts of the working group was concentrated on this task. The range of the results obtained by the different authors is considerable. This is partly due to the uncertainties in the basic data and partly in the individual subjective weighting of certain parameters.
\end{abstract}

\section{Introduction}

A study group of the European Seismological Commission was established at its XX General Assembly in 1986 in Kiel, Germany, for a joint project called «Test Regions for European Seismic-Hazard Assessment (TERESA)». The main goal of this project was to provide a common forum for investigation and comparison of approaches for the seismic-hazard assessment, currently applied in various countries in central Europe. The working group soon concentrated on methods and computer programs which allow one to calculate the probability of occurrence for various levels of ground-motion parameters, preferably seismic intensity.

The main steps in the project were:

1) selection of two test areas, one with high and one with low seismicity;

2) compilation and distribution of a common data-base for all groups;
3) identification and evaluation of the different available methods;

4) preparation of individual input data sets by each group;

5) presentation and comparison of the results for both test regions.

The two test areas, which have been chosen finally, are depicted in fig. 1. The TERESA group agreed that both areas provide an ideal background for a common study. Both areas have been hit by damaging earthquakes in history.

In 1987 and 1988 three workshops have been organized in Prague, Milano and Zurich, respectively. The final results were presented to a larger audience in 1988 at the XXI General Assembly of the European Seismological Commission in Sofia.

\section{The Sannio-Matese case}

The selected test area, called Sannio Matese 
in this study, is situated in southern Italy east of Napoli (see fig. 1) with Benevento in the center, and covers approximately $15000 \mathrm{~km}^{3}$. It is one of the most active seismic regions in Italy, characterized by destructive earthquakes reaching magnitudes up to $M_{\mathrm{S}}=6$ to 7 (intensities IX to XI MCS). Most of the strong earthquakes in this area occur within a relatively narrow zone of about $(30 \div 50) \mathrm{km}$ width, approximately following the axis of the Apenninic chain.

The most recent earthquake in this area (Irpinia, 20 November 1980, $M_{\mathrm{S}}=6.5, h=10 \mathrm{~km}$ ) is located in the region, as well as the strong historical earthquakes in 1694 (maximum intensity = X), 1732 (X), 1910 (IX-X) and 1930 (X). Other strong events, described in various chronicles, are also lying in the vicinity: 1688(XI), $1702(\mathrm{X})$, 1805 (X), 1857 (X), 1962 (IX).

In short, the test area in fig. 2 was selected by the working group as prime test area mainly because of the following reasons:

- the relative high potential for large earthquakes;

- the associated risk to urban areas such as Benevento, Napoli, Potenza, etc.;
- the good historical data-base available for this area;

- the experience of the Italian groups from other investigations in the region (see e.g. De Vivo et al., 1979).

In particular five locations have been selected for direct comparison of the different outputs: Benevento, Boiano, Melfi, Pomigliano and Lucera (see fig. 2). Three of these cities (Benevento, Boiano and Melfi) are situated directly in the zone of highest activity in the Apennines, while Lucera and Pomigliano are located about $50 \mathrm{~km}$ off to the east and west, respectively. The results for the first three locations should be very sensitive to the activity rate adopted for the central zone, and the latter two locations depend mainly on the attenuation parameters.

\section{Common data-base}

Seismic intensity was chosen as ground-motion parameter by practically all members, because it was regarded as the most relevant measure contained in the available catalogues

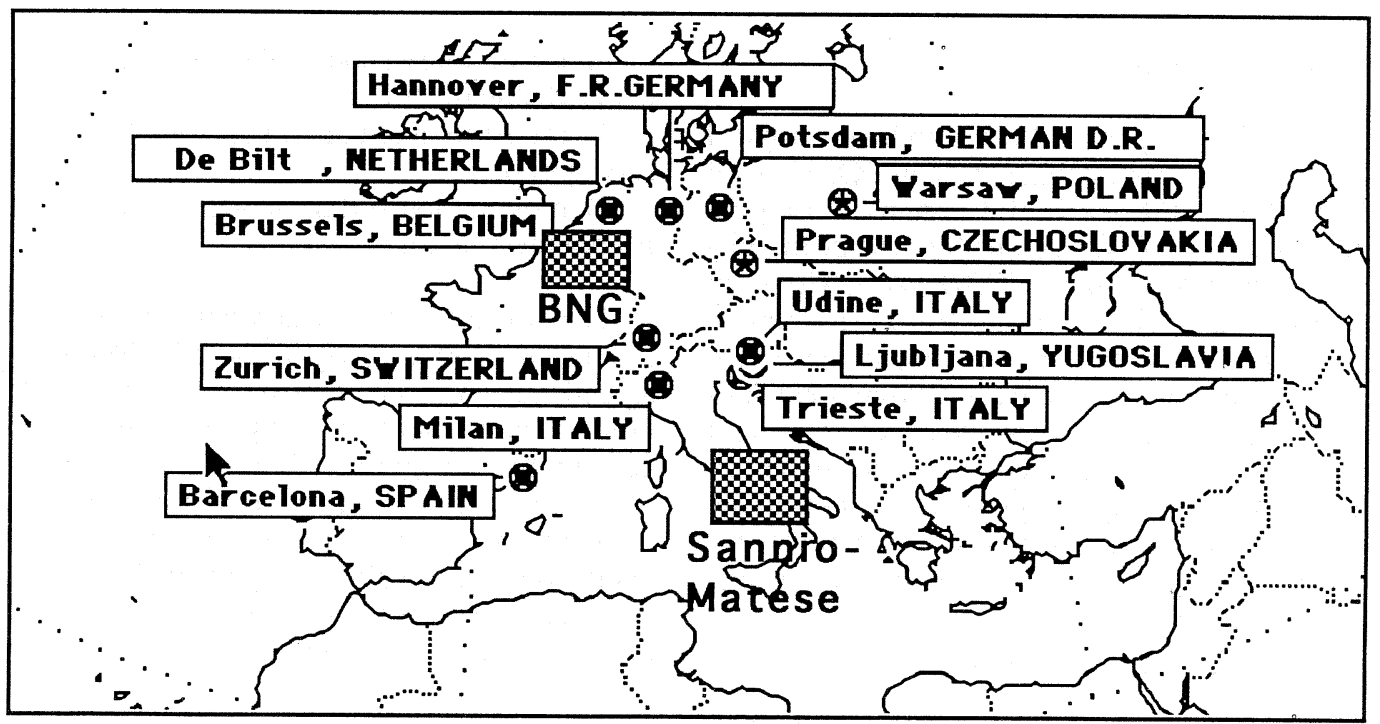

Fig. 1. Selected test areas for the TERESA project: southern Italy (Sannio-Matese region) and north-central Europe (Belgium-Netherlands-Germany border zone). The origins of the participating members are also indicated. 


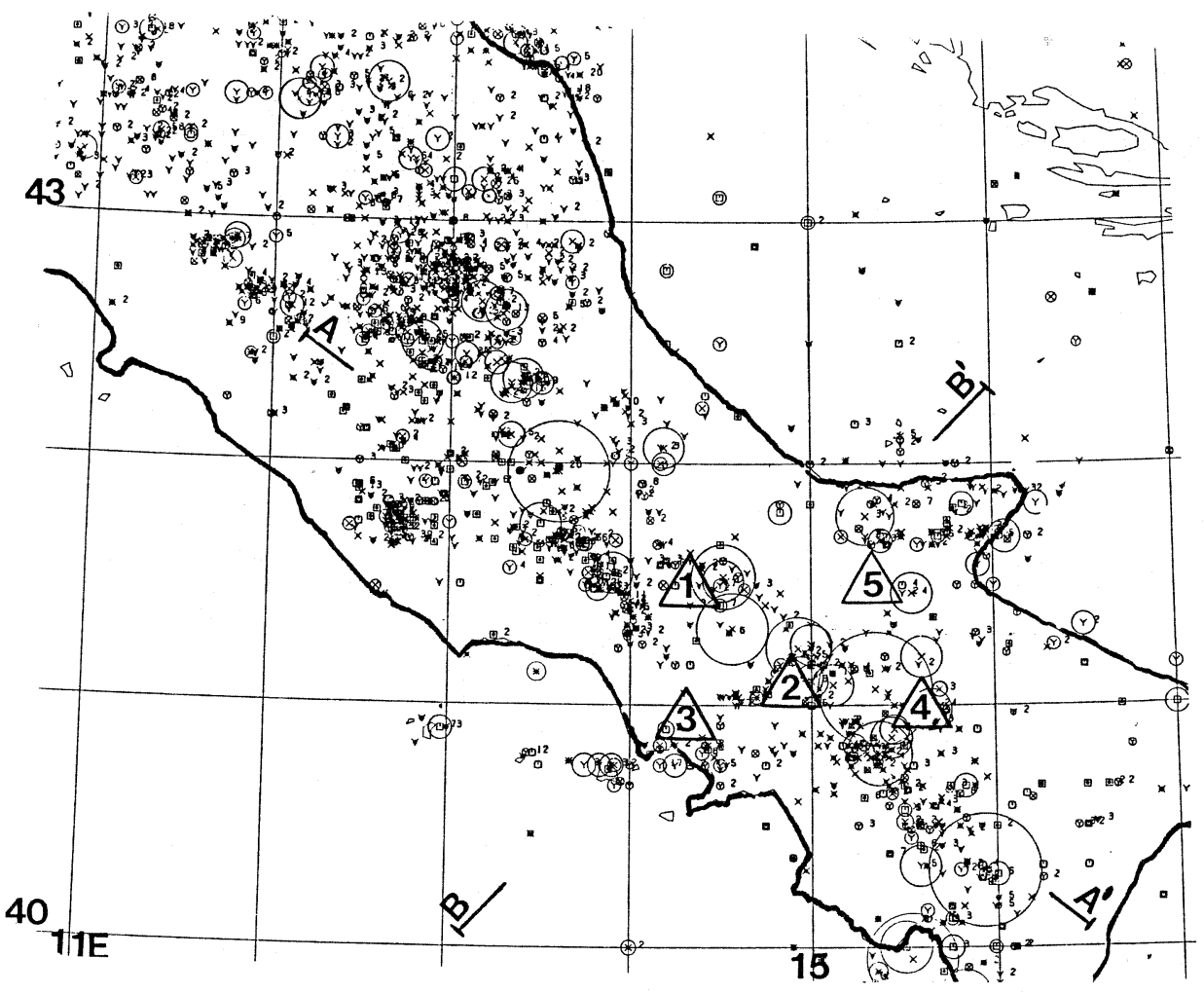

Fig. 2. Epicenter map (1000-1980) of the Sannio-Matese test area (Postpischl, 1985b). The triangles refer to the test sites: 1-Boiano, 2-Benevento, 3-Pomigliano, 4-Melfi, 5-Lucera. AA' and BB' refer to the cross-sections in fig. 3.

with respect to the size and effects of the historical earthquakes. This restricted the analysis and calculations essentially to macroseismic parameters and thereby naturally limited the choice of applicable methods.

The data set, which was distributed at the beginning of the project to all groups, consisted of:

a) an earthquake catalogue 1000-1980 (Postpischl, 1985a);

b) an atlas of isoseismal maps (Postpischl, 1985b); 1987);

c) neotectonic maps (Ambrosetti et al.,

d) reference list of papers and other available publications with information on seismotectonics, source mechanisms and geophysical data.

\section{Approaches and methods}

During the first period of the project it was found that the major differences in the approaches chosen by each group exist in the preparation of the input parameter set. It was therefore not decided to have a common input parameter set, but rather to discuss the reasons for the existing variations among the participants and to investigate its effects on the calculations.

One part of the algorithms used during the project is based on previous programs (Merz and Cornell, 1973; McGuire, 1976), which were adopted for the probabilistic determination of seismic hazard by several groups. Most groups had already experience in using these programs. Other algorithms have recently been developed by WG-members and further improved during 

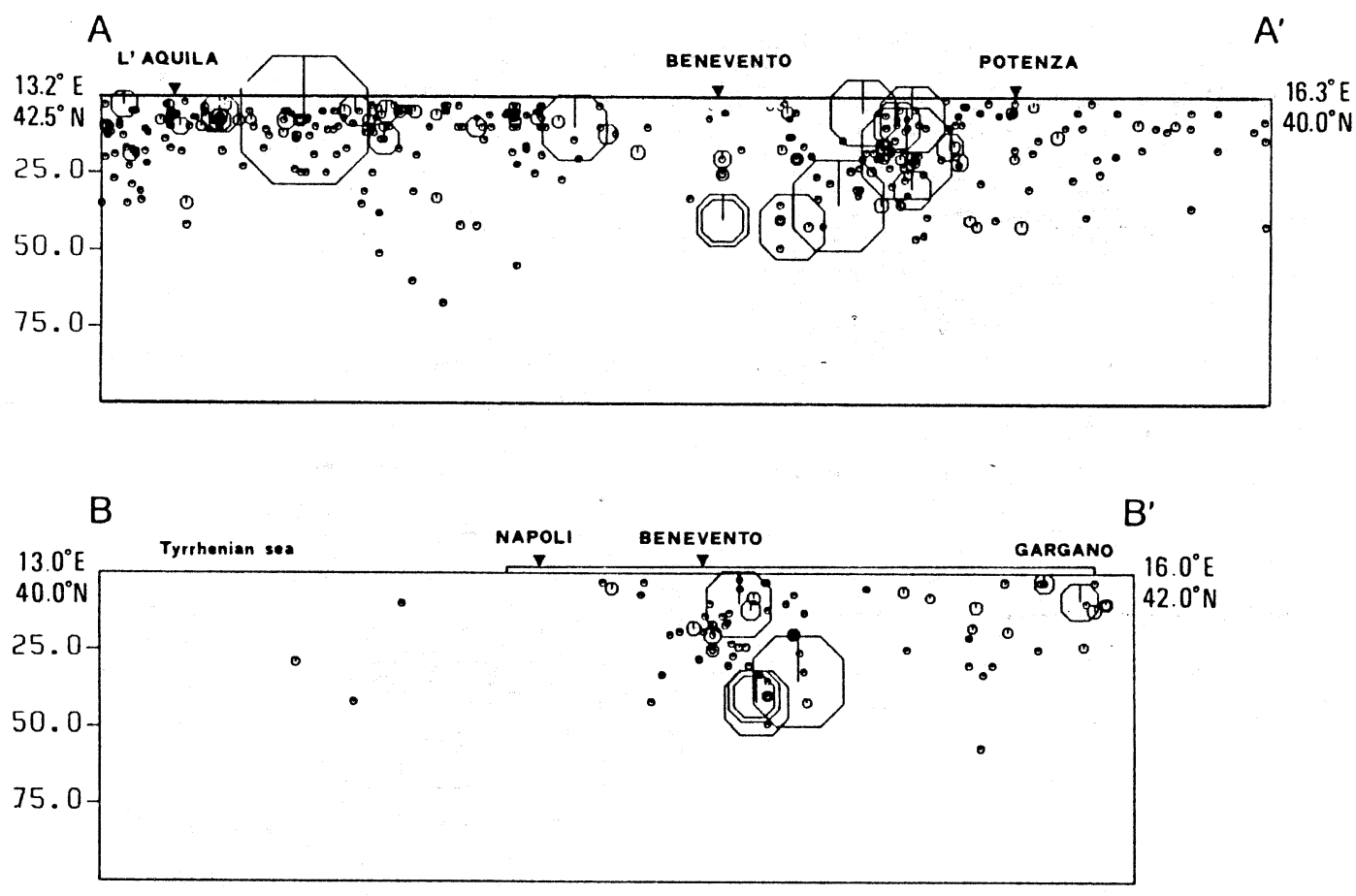

Fig. 3. Vertical cross-sections of the Sannio Matese area. AA' $100 \mathrm{~km}$ wide along the Apenninic trend, BB' $100 \mathrm{~km}$ wide perpendicular to the Apenninic trend.

the workshops.

The programs used during the workshops and their underlying philosophies are described in the following.

- Cornell's algorithm, the very popular computer program SRAMSC (McGuire, 1976), RISK4A (Algermissen et al., 1976) and some modified versions. These approaches require a more or less exact definition of seismic-source zones, as well as attenuation relations of groundmotion parameters and frequency-intensity distributions for each source zone. SRAMSC modifications refer to specific attenuation laws (e.g., Koveslighety-Sponheuer type) and azimuth variations (Barbano et al., 1989a; Lapajne et al., 1989; Mayer-Rosa, 1989; Schenk et al., 1989; Siro and Slejko, 1989).

- Methods which consider only the strongest earthquakes in their epicentral position and treat the seismicity according to the theory of the extreme values, mainly Gumbel 1 and Gumbel 3 distributions (Barbano et al., 1989a; Siro and Slejko, 1989).

- Mixed approach, in which first the $a$ priori hazard is obtained by considering the effect of very wide and contiguous seismic zones and afterwards the first output is improved by recovering the information from every single event by using Bayes' theorem (Garcia Fernandez and Egozcue, 1989).

- Related mainly with input data preparation, Kijko's approach considers different divisions of the catalogue, which contain either extreme values or complete data sets. It gives the maximum likelihood estimation of the parameters of the source zones (Kijko and Sellevoll, 1989).

\section{Seismogenic zoning}

General guidelines to define seismogenic zones, often also called source zones, which are required in most seismic-hazard assessment pro- 

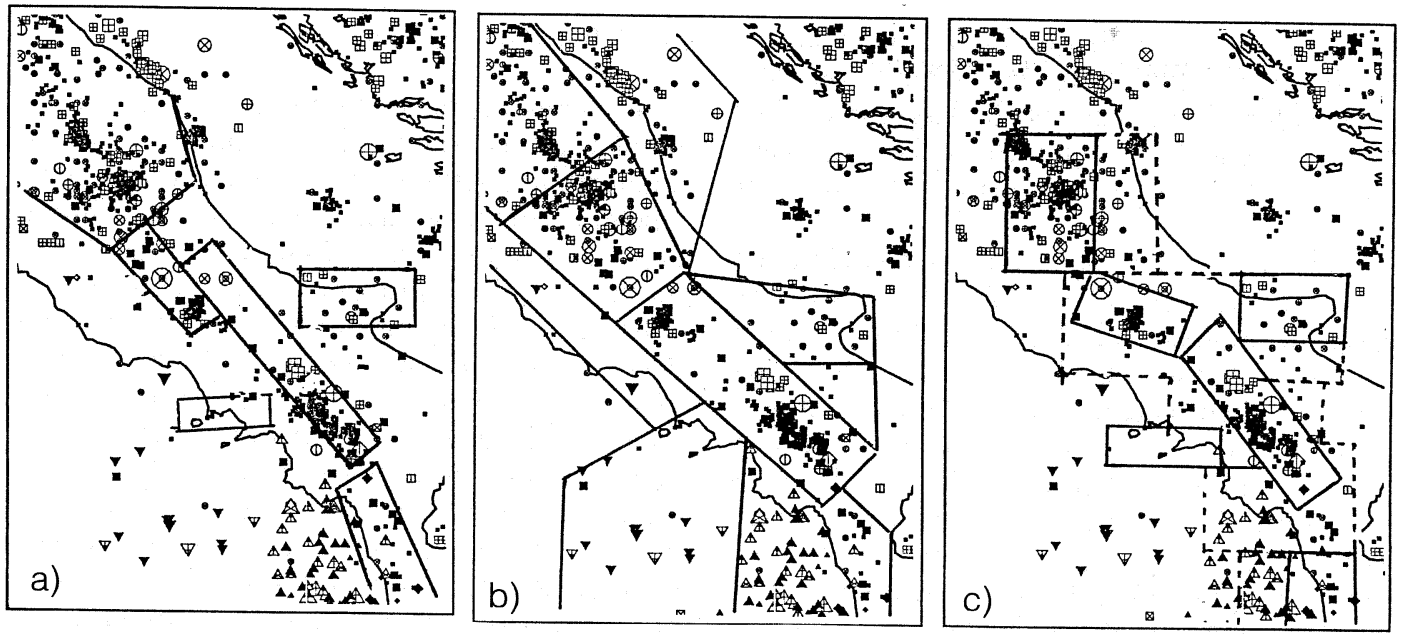

Fig. 4. Typical models of seismogenetic zonation in the TERESA working group: a) «narrow», b) «wide», c) «mixed zoning».

grams, could not be established. The different authors followed more or less empirical and highly subjective rules in delineating these zones, mainly by taking into account the distribution of historical as well as recent instrumental epicenter maps. Tectonic features influenced, if any, the overall size of the zones. The TERESA group agreed in general on the fact that the standard tectonic maps available for the region do not contribute significantly to the reliability of the definition of a source zone. One of the reasons is that the assumed engine for the seismicity lies deep under the Apenninic nappes. All authors were drawing heavily on epicentral maps and depth distributions of foci, where they have been considered reliable enough. Figure 4 shows the three pricipal approaches:

a) Narrow zoning, in which only the most active areas have been included. The area with low density of epicenters is considered as background, i.e. as a source zone which is at least 10-20 times larger than the primary source zones (Mayer-Rosa, 1989).

b) Wide zoning, where the test area and the surrounding regions are divided into contiguous zones of varying size, governed by the overall activity (Barbano et al., 1989a; Schenk et al., 1989).

c) Narrow zones, where earthquake activity of a somewhat larger area is concentrated to the smaller zone, taking into account that the locations of historical events are not precise enough to exclude them to the background (Lapajne et al., 1989; Siro and Slejko, 1989).

All groups had the feeling that it was possible to develop zoning models which are able to describe the main features of the seismicity patterns. Several regions with distinctive seismological characteristics have been recognized by all groups: the Gargano zone on the Adriatic coast, the volcanic zone of Campania near Napoli, the Abruzzi Apennines zone, and the southern Apennines zone.

\section{Seismic input parameters}

The main difficulty was to assess the completeness and homogeneity of the catalogues (Carrozzo et al., 1973; Postpischl, 1985b) and even more the data sets selected for the different source zones. A simple analysis of the catalogues shows (Mayer-Rosa, 1989) that the data-base can only be considered fairly complete for the strongest events with intensity $\geq$ VIII, for events with intensity $\geq V I$ within the last 300 years, and for intensity $\geq \mathrm{V}$ within the last 100 years. As a particularity of the Italian catalogue it was found 
that sometimes the distribution of the events in certain time periods seemed to be more complete for smaller events than for the larger ones. For these zones Kijko's approach (Kijko and Sellevoll, 1989) seems to work better than the other methods.

Most researchers agreed that aftershocks must be identified, but rather different ways in the practical approach have been followed. Some authors treated aftershocks as independent events and used them accordingly in the calculations. Other authors used time windows between $(1 \div 6)$ months for their extraction. As the most reasonable dimension of the corresponding space window, the supposed error in the location of historical earthquakes $((20 \div 50) \mathrm{km})$ was taken.

With respect to the estimation of the maximum possible earthquake intensity two general philosophies are followed. One part of the authors considered no maximum upper bound for seismic intensities (Garcia Fernandez and Egozcue, 1989; Mayer-Rosa, 1989). Another view was taken, e.g., by Barbano et al. (1989a), who related the upper limit to the maximum observed earthquake in a zone.

\section{Attenuation relations}

Probably the most important element in seismic-hazard assessment is the choice of typical attenuation functions for the ground-motion parameters. This relationship is obviously azimuth dependent in the Sannio-Matese area, as shown in the atlas of isoseismal maps (Postpischl, 1985a). Practically all authors assumed azimuth dependence with low attenuation along the strike of the Apennines and high attenuation perpendicular to it. Also most groups adopted the Sponheuer-Kovesligethy formulation with an azimuth-dependent attenuation coefficient $\alpha$, computed from averaged isoseismals. Figure 5 shows the typical attenuation curves used in the Apenninic and anti-Apenninic direction compared to other European regions.

Siro and Slejko (1989) proposed $\alpha$-coefficients varying by the factor of 10 for both directions, i.e. 0.005 parallel to the Apennines, and 0.05 in the transverse direction. Barbano et al. (1989a) used different relations for the near and far field of each seismic source zone, thus introducing two $\alpha$ 's for the Apenninic and two for the

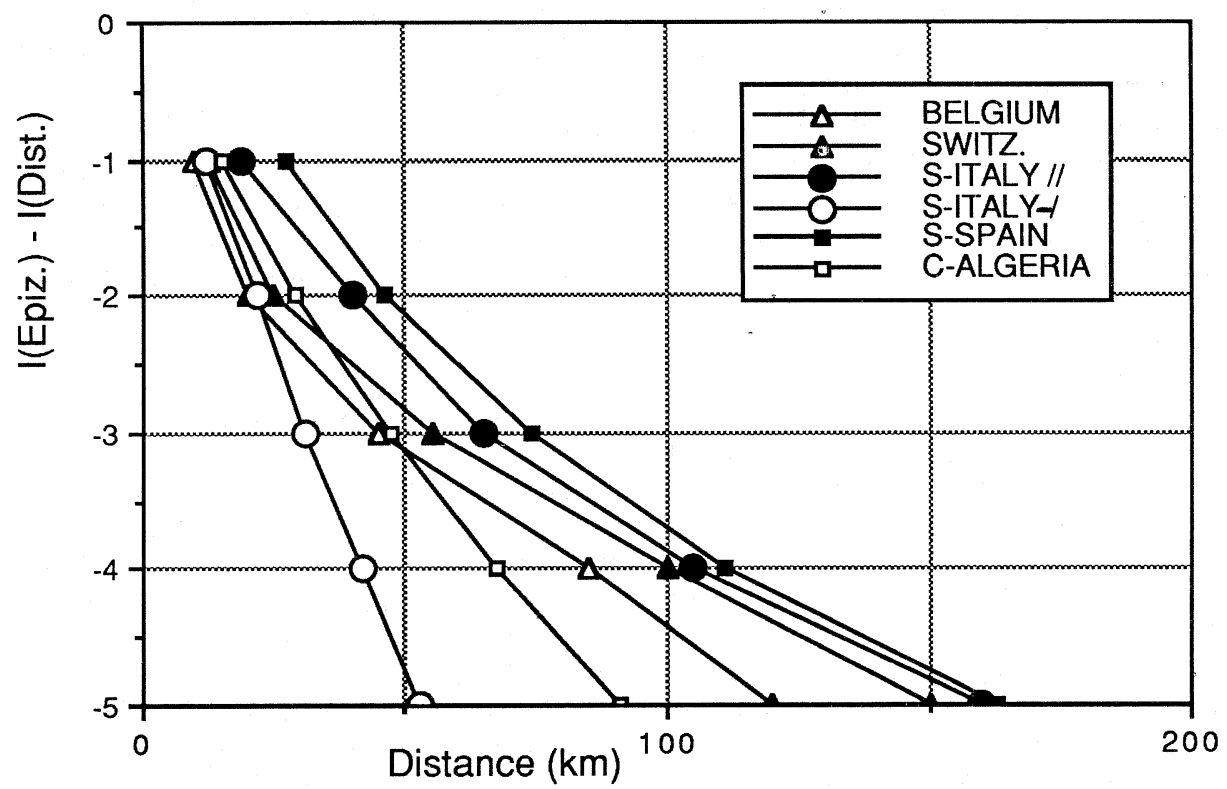

Fig. 5. Typical intensity attenuation $\left(I_{0}-I\right)$ adopted for the Apenninic and anti-Apenninic direction (Barbano et al., 1989b), compared to other European-Mediterranean regions (Mayer-Rosa, 1989). 
anti-Apenninic direction. Lapajne et al. (1989) adopted a relation in form of three log-linear equations, which represent the different slopes in the intensity-distance curves in 1) the epicentral region, 2) the near field and 3 ) the far field $(>100 \mathrm{~km})$.

In order to take into account the considerable scatter of the macroseismic data, a normal distribution was taken into account for the intensity attenuation curves. Typical $s$-values of \pm 0.5 intensity degrees for all zones and all distances have been adopted, e.g., by Mayer-Rosa (1989), and much smaller values, e.g., by Barbano et al. (1989a).

\section{Results}

As outcome of the differing approaches (e.g., in the conservativism of zoning, maximum possible earthquake, scatter of the data) significant diversification in the results is observed (Barbano et al., 1989b). Table I illustrates this fact showing the computed return periods for intensity VIII MCS at five localities chosen for this purpose. For simple comparison Garcia and Egozcue (1989) just counted the number of occurrences of intensity VIII at each place. The values in Table I only partly represent the differences in the results. A more complete picture reveals the probability distributions from intensity VI to X in fig. 6.

For the locations in the highest active source zone (Benevento, Boiano and Melfi), as to be expected, the largest hazards are obtained. This is evident in those solutions where narrow zoning was used leading to even more conservative results. The hazard figures for Pomigliano and Lucera on the other side depend very much on the attenuation relationships.

Different applications of the Cornell algorithm (SRAMSC and RISK4A) give similar charcteristics of hazard distribution, but the absolute levels still vary considerably.

In general, it was found that the extreme value method (Gumbel 1 and Gumbel 3 distributions) results in much lower hazards (higher return periods) than the Cornell method. This is demonstrated in the results of Barbano et al. (1989a) and Siro and Slejko (1989), who both used methods with similar input parameter sets.

The differences in the shape of the probability curves towards larger intensities are most probably due to the different earthquake distributions and to the different upper bounds of possible earthquake size.

\section{Application of fault-rupture models}

Another method for assessing the seismic hazard has been applied in addition to the presented results of the TERESA project, with the goal of testing the stability of the results obtained. In the FRISK (McGuire, 1978) model, the fault rupture length is introduced as a function of earthquake magnitude. Ground-motion estimates are made using the earthquake magnitude and closest distance from the site to the rupture zone. Probabilistic uncertainties in the maximum possible magnitude, in the location of the rupture zone on

Table I. Return periods (years) for intensity VIII MCS in the Sannio-Matese area.

\begin{tabular}{llccccc}
\hline \hline Reference & Method & Benevento & Boiano & Pomigliano & Lucera & Melfi \\
\hline Barbano et al. & SRAMSC & 52 & 73 & 122 & 125 & 75 \\
& Gumbel-1 & 142 & 238 & 714 & 588 & 210 \\
Garcia and & Egozcue & 51 & 51 & 80 & 77 & 64 \\
Egozcue & counting & 40 & 40 & 70 & 94 & 47 \\
Lapajne et al. & SRAMSC & 79 & 88 & 312 & & 95 \\
Mayer-Rosa & SRAMSC.mod & 23 & 27 & 120 & 100 & 66 \\
Schenk et al. & SRAMSC & 34 & 65 & 83 & 120 & 49 \\
Siro and Slejko & RISK4A & 24 & 24 & 333 & 77 & 77 \\
& Gumbel-1 & 71 & 83 & 200 & 143 & 83 \\
& Gumbel-3 & 67 & 91 & 333 & 167 & 83 \\
\hline
\end{tabular}



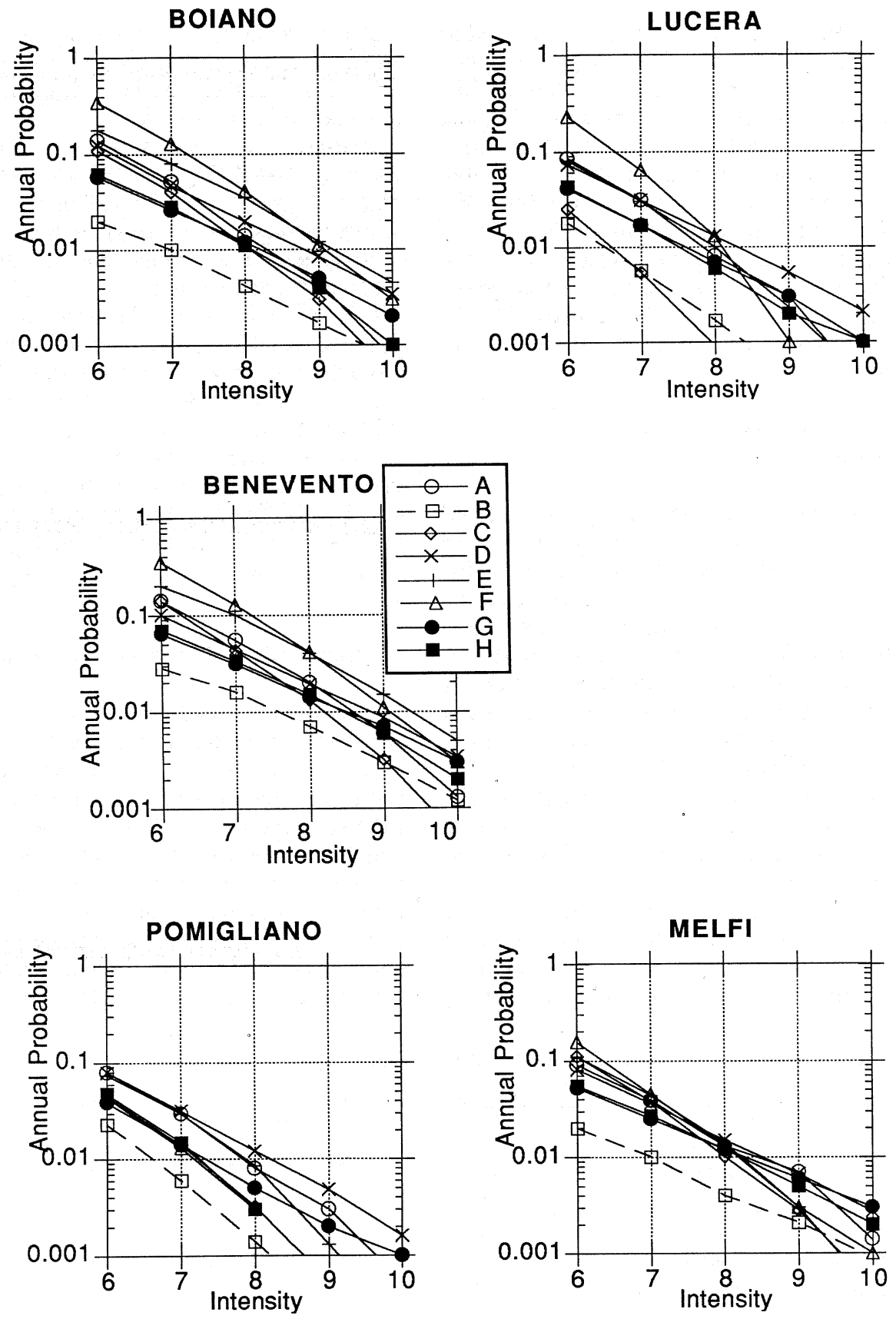

Fig. 6. Composition of results of different authors: probability of annual occurrence for five selected sites. (A, B: Barbano, et al. 1989b; C: Lapajne et al., 1989; D: Garcia and Egozcue, 1989; E: Mayer-Rosa, 1989; F: Siro and Slejko, 1989.) 
the fault, and in the expected ground motion are accounted for in the calculations. The model estimates seismic hazard at a test site of interest by a numerical evaluation using the total probability theorem. The program FRISK has been applied to Sannio-Matese considering a schematic tectonic hypothesis based on the seismotectonic model of the Apennines (Patacca and Scandone, 1990) and on the spatial distribution of seismicity.

In fig. 7 a schematic model of Southern Italy for hazard calculation purposes is presented. The events occurring within the rectangular zones no. 1-8 in fig. 7 have been fully associated with one or two large faults identified in each zone. As the exact location of fault no.5 (southern Apennines) is not supported by strong evidences, two different models have been used: the first one by considering only fault no.5a with $100 \%$ prob- ability of existence, the second one by considering two faults with $50 \%$ probability each. The seismicity parameters of the faults (annual rate and b-value) have been computed from the Italian catalogue (Postpischl, 1985b) using the time span 1900-1980 and considering magnitude 3.0 as threshold value. For all faults the average depth of $12 \mathrm{~km}$ has been imposed and the relation by Coburn et al. (1987) for magnitude-rupturelength for the Irpinia 1980 earthquake has been used. To transform the acceleration into intensities the relationship for the Irpinia earthquake (Siro and Slejko, 1989) has been applied.

The general hazard picture is similar to the previous results, with a pronounced NW-SE elongation of the area with maximum intensity $\mathrm{X}$ $\operatorname{MCS}(=277 \mathrm{Gal})$. The differences from considering either one or two faults to describe the seismicity in the central part of the study area, show

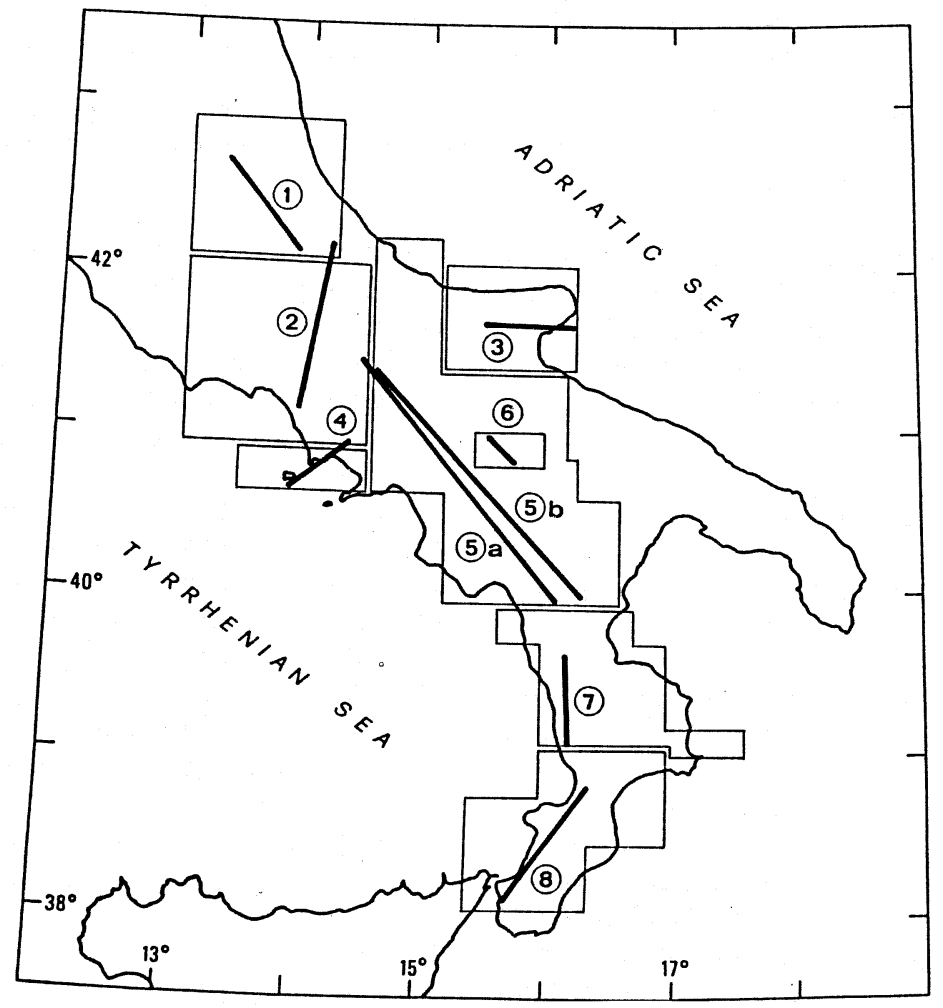

Fig. 7. Schematic seismotectonic zonation and faults adopted for seismic-hazard evaluation: 1)= Gran Sasso, 2) $=$ Ancona-Anzio, 3) $=$ Gargano, 4) $=$ Vesuvio, 5a,b) = southern Apennines (see text), 6)= Vulture, 7)= Crati, 8)= Calabria; the short fault-lines 4 and 6 are introduced to represent the activity of the respective areas. 


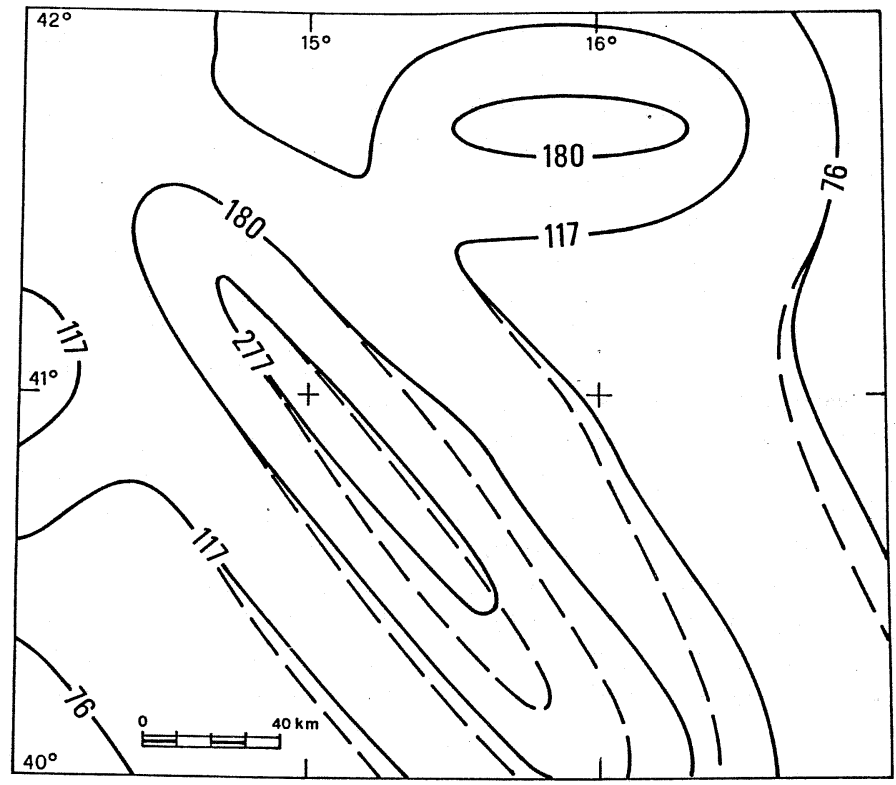

Fig. 8. Maximum acceleration (in Gal) expected not to be exceeded with $68 \%$ probability in 200 years, calculated for the two models described in the text. Dashed line refers to the one-fault model (5a), solid line to the two-fault model (5a and $5 b$ ).

up only in the small zone in which the faults are placed (fig. 8): the introduction of only one fault (dashed lines) enlarges the area of $277 \mathrm{Gal}$ only at the southernmost edge. Outside the central zone the differences are negligible.

\section{Summary and conclusions}

The results obtained in the TERESA project can be summarized as follows.

- The methods for calculation are less important than the careful preparation of the input parameters.

- Main uncertainties in seismic-hazard assessment come from personal judgements involved in the preparation of the input parameters and the obvious lacking of models of the earthquake process. Models which are able to describe statistically the seismicity in an area for a defined time window in the future are urgently needed.

- Most of the problems introduced in Prague at the first TERESA workshop (Prague, 1987) have not been solved, but they have been examined thoroughly. The profit of the project and workshops was clearly a harmonization of methods for preparing input data and the demonstration of weak points in the procedure.

- Intensity as a parameter for ground motion is of limited use to engineers, who are the main addressees of the results. Intensities have to be converted into physical parameters, which is a very doubtful undertaking. Correlation of relevant measured strong-motion data with intensity estimations is needed.

- Application of the results to codes for the test area was investigated by Grazioli and Zonno (1988) using an expert system technique CZAR, developed by Meroni and Zonno (1990). For details please refer to the respective publications.

\section{REFERENCES}

Algermissen, S.T., D.M. Perkins, W. Isherwood, D. Gordon, G. REAGOR and C. HowARD (1976): Seismic risk evaluation of the Balkan region, in Proceedings of the Seminar on seismic zoning maps, Unesco, Skopje, pp. 172-240. 
Ambrosetti, P., C. Bartolini, C. Bosi, N. Carraro, N. Ciaranfi, F. Ghisetti, G. Papani, L. Vezzani, A. ZanFERRARI and N. ZTTELLINI, (1987): Neotectonic Map of Italy, CNR, Quad. Ric. Sci., 114/4.

BARBANO, M.S., F. Colombo and G. Zonno (1989a): Preliminary results of seimic hazard assessment in the SannioMatese area, Natural Hazards, 2, 307-328.

Barbano, M.S., J.J. EgOzCue, M. Garcia Fernandez, A KijKo, J. Lapajne, D. Mayer-Rosa, V. Schenk, Z. Schenkova, D. SlejKo, and G. Zonno (1989b): Assessment of seismic hazard for the Sannio-Matese area of Southern Italy- A Summary, Natural Hazards, 2, 217228.

Carrozzo, M., G. De Visintini, F. Giorgetti and E. IACCARINO (1973): General, catalogue of Italian earthquakes, Com. Nazionale Energia Nucleare, CNEN-RT/PROT (73) 12.

Coburn, A., R. SPEnCE and G. ZuCCARo (1987): Seismic Risk to Populations in Campania, SISMA progress report, April 1987.

Garcia Fernandez, M. and J.J. Egozcue (1989): Seismic hazard assessment in TERESA test areas based on Bayesian technique, Natural Hazards, 2, 249-266.

GrAZIOLI, A. and G. ZoNNO (1988): Nuove tecnologie per l'analisi dei parametri di pericolosità sismica: prime applicazioni, Atti del $7^{\circ}$ Convegno GNGTS, Roma, 1988.

KIJKO, A. and M. SELlevoll (1989): Estimation of earthquake hazard parameters from incomplete data files. Part I: Utilization of extreme and complete catalogues with different threshold magnitudes, Bull. Seismol. Soc. Am. 79, 645- 654 .

LAPAJNe J., Z. Breska, M. GodeC and M. ZrvciC (1989):
Results of seismic hazard assessment for Sannio-Matese region, Natural Hazards, 2, 363-386.

MAYER-RoSA, D. (1989): Critical parameter investigation for earthquake hazard calculation in the TERESA test area of Sannio-Matese, Natural Hazards, 2, 237-248.

McGUIRE, R. (1976): FORTRAN Computer program FOR Seismic Risk Analysis (SRAMSC), U.S. Geological Survey, Open-File Report, pp. 76-67.

McGUIRE, R. (1978): FRISK. Computer program for seismic risk analysis, using faults as earthquake sources, USGS Open file report 78-1007.

MERONI, F. and G. ZonNo (1990): Stato di implementazione del prototipo CZAR in NEXPERT, Atti del $2^{\circ}$ Workshop «Informatica e Scienze della Terra», Sarnano, 1990.

MERZ, H. and C.A. CoRNELl (1973): Seismic risk analysis based on a quadratic magnitude-frequency law, Bull. Seismol. Soc. Am., 63, 1999-2006

POSTPISCHL, D. (Editor) (1985a): Atlas of Isoseismal Maps of Italian Earthquakes, CNR, P.F. Geodinamica(Graficoop, Bologna).

PosTPISCHL, D. (Editor) (1985b): Catalogo dei terremoti Italiani dall'anno 1000 al 1980, CNR. P.F. Geodinamica, Quad. Ric. Sci., 114/2B.

PATACCA, E. and P. SCANDONE (1990): Seismical hazard-seismotectonic approach, ENGEOL, Bari, April 1986, Vol. 5, pp. 103-115.

SCHENK, V., Z. SchENKova, F. MANTLIK and P. KotNAUER (1989): Seismic hazard assessment for two test areas «Central Italy» and Belgium- Netherlands- F.R.Germany, Natural Hazards, 2, 267-288.

SIRO, L. and D. SLEJKo (1989): On seismic hazard of SannioMatese (Southern Italy), Natural Hazards, 2, 329-348. 